\title{
STRATEGI PENGEMBANGAN KAWASAN EKOWISATA KEDAH KECAMATAN BLANGJERANGO KABUPATEN GAYO LUES
}

\author{
(The Develement Strategy of the Kedah Ecotourism Area,Blangjerango District,Gayo \\ Lues District)
}

\author{
Mawardi $^{1}$, Ashabul Anhar ${ }^{2}$ Iqbar $^{3 *}$ \\ ${ }^{1}$ Program Studi Kehutanan PSDKU Unsyiah Gayo Lues, Universitas Syiah Kuala \\ ${ }^{2}$ Program Studi Kehutanan, Fakultas Pertanian, Universitas Syiah Kuala \\ ${ }^{3}$ Program Studi Kehutanan, Fakultas Pertanian, Universitas Syiah Kuala \\ Mawardi2019x@gmail.com.
}

\begin{abstract}
Abstrak. Pengembangan pariwisata sebagai andalan perekonomian nasional dalam operasionalnya bertumpu pada potensi alam, potensi budaya, dan kehidupan masyarakat di lokasi pengembangan wisata. Penelitian ini betujuan untuk mengetahui kondisi ekowisata Kedah Gayo Lues sebagai kawasan wisata serta mengetahui potensi yang ada di wisata Kedah Gayo Lues, pengembangan ekowisata yang ideal dimasa mendatang dan memformulasikan strategi pengembangan wisata Kedah Gayo Lues sesuai dengan konsep ekowisata. Metode yang digunakan dalam penelitian ini yaitu metode Purposive Sampling dengan pengambilan sampel secara sengaja dan didasarkan atas adanya tujuan tertentu. Sampel terpilih merupakan stakeholder yang mempunyai keterkaitan dengan kawasan ekowisata Kedah.Wawancara dan pengisian kuisioner melibatkan pengelola kawasan ekowisata Kedah, pemerintah, akademisi, pemerintah Desa, masyarakat setempat, pengunjung dan pemandu wisata. Identifikasi faktor internal pengelolaan ekowisata Kedah terdapat permasalahan pengelolaan yaitu kurangnya dukungan dari pemerintah tentang pengelolaan ekowisata Kedah, belum adanya pengurus yang terstruktur dalam upaya pengembangan wisata Kedah, fasilitas yang belum memadai di wisata Kedah, tidak adanya ciri khas khusus yang dapat menghibur pengunjung seperti kesenian tradisional dan sebagainya, tingkat sumberdaya masyarakat setempat dalam pengembangan wisata Kedah masih tergolong lemah.
\end{abstract}

Kata Kunci : Strategi Ekowisata, Pengembangan Wisata, Kedah.

\begin{abstract}
Tourism development as the mainstay of the national economy in its operations rests on natural potential, cultural potential, and community life in tourism development locations. This study aims to determine the condition of Kedah Gayo Lues ecotourism as a tourist area and to know the potential that exists in Kedah Gayo Lues tourism, to develop ideal ecotourism in the future and to formulate a tourism development strategy for Kedah Gayo Lues according to the ecotourism concept. The method used in this research is purposive sampling method with deliberate sampling and is based on the existence of certain objectives. The selected sample is a stakeholder who has a relationship with the Kedah ecotourism area. Interviews and questionnaires involving the Kedah ecotourism area manager, government, academics, village government, local communities, visitors and tour guides. Identification of internal factors in Kedah ecotourism management, there are management problems, namely the lack of support from the government regarding the management of Kedah ecotourism, the absence of a structured management in efforts to develop Kedah tourism, inadequate facilities in Kedah tourism, the absence of special characteristics that can entertain visitors such as traditional arts and so, the level of local community resources in developing Kedah tourism is still relatively weak.
\end{abstract}

Keywords: Ecotourism Strategy, Tourism Development, Kedah 


\section{PENDAHULUAN}

\subsection{Latar Belakang}

Pengembangan pariwisata sebagai andalan perekonomian nasional dalam operasionalnya bertumpu pada potensi alam, potensi budaya, dan kehidupan masyarakat di lokasi pengembangan wisata.Hubungan timbal balik antara alam, budaya, dan kehidupan masyarakat harus saling menguntungkan. Pariwisata harus mampu meningkatkan kondisi ekowisata di dalam budaya masyarakat serta menumbuhkan ekonomi dan matapencaharian ditempat tujuan (Prasiasa, 2011).

Pariwisata adalah segala sesuatu yang berhubungan dengan wisata, termasuk pengusahaan objek dan daya tarik wisata serta usaha-usaha yang terkait di bidang tersebut. Kepariwisataan mempunyai peranan penting untuk memperluas dan pemerataan kesempatan berusaha dan lapangan kerja, mendorong pembangunan daerah, memperbesar pendapatan nasional dalam rangka meningkatkan kesejahteraan, kemakmuran rakyat, memupuk rasa cinta tanah air, dan memperkaya kebudayaan nasional (Undang-Undang Republik Indonesia Nomor 10, 2009).

Provinsi Aceh adalah salah satu daerah tujuan wisata (DTW) di Indonesia yang memiliki banyak potensi yang dapat dikembangkan. Provinsi Aceh juga memiliki beberapa adat istiadat, bahasa dan kesenian, panorama alam serta tempat-tempat maupun gedung bersejarah. Di antara kabupaten yang ada di Aceh, Gayo Lues merupakan salah satu kabupaten yang memiliki potensi panorama alam, budaya, dan kehidupan masyarakat yang unik. Hal ini menjadi daya tarik wisata bagi wisatawan baik lokal maupun manca negara.

Kawasan konservasi, kawasan suaka alam maupun kawasan hutan lindung, merupakan destinasi yang diminati oleh wisatawan baik lokal maupun mancanegara. Lokasi ini memiliki keanekaragaman flora, fauna, fenomena alam yang indah, objek budaya dan sejarah serta kehidupan masyarakat lokal yang unik. Pemanfaatan sumberdaya alam dan lingkungannya serta kepedulian pada masyarakat sekitar pada kawasan-kawasan konservasi sejalan dengan visi pengembangan ekowisata yaitu konservasi keanekaragaman hayati dan ekosistemnya serta pemberdayaan masyarakat lokal (Fandelli dan Mukhlison, 
2000).

Kedah adalah salah satu objek wisata alam berupa hutan hujan tropis yang terletak di kaki Gunung Leuser bagian Gayo Lues. Secara administrasi Ekowisata Kedah berada di Desa Penosan Sepakat, Kecamatan Belangjerango Kabupaten Gayo Lues. Wisata Kedah merupakan akses bagi para wisatawan untuk mendaki salah satu bagian dari Gunung Leuser. Keindahan serta keasrian Kedah bukan hanya semata lokasi ini pintu gerbang menuju Leuser akan tetapi juga memiliki keunikan tersendiri, diantaranya hutan yang masih sangat bagus, aliran sungai yang belum dilintasi oleh pemukiman penduduk, udaranya yang sejuk, pemandangan yang indah serta jauh dari kebisingan.

Kondisi Kedah saat ini hanya ada aktivitas pengelolaan ekowisata berupa penyedia jasa pemandu pendakian Gunung Leuser dan jasa penginapan yang kontruksinya alami. Pengelolaan kawasan wisata Kedah masih belum berjalan sebagaimana diharapkan.Hal ini mengakibatkan koordinasi antar sektor dan lintas sektormenjadi tidak efektif.Disamping itu keterlibatan masyarakat dalam pengelolaan lingkungan juga masih rendah dan belum mendukung dalam melestarikan fungsi utama kawasan ekowisata Kedah sebagai daerah tujuan wisata.Kurangnya perhatian pemerintah dan pemangku kepentingan lainya dalam mengelola kawasan wisata Kedah telihat denganbelum tersedianyafasilitas yang memadai seperti jalan menuju lokasi, fasilitas MCK (Mandi, Cuci dan Kakus), tempat beribadah yang belum tersedia dengan kondisi yang memadai, fasilitas penjualan, cindramata dan juga fasilitas edukasi pengunjung. Hal ini mengakibatkan perkembangan ekowisata menjadi terhambat.Meskipun kondisi Kedah masih jauh dari gangguan manusia, namun kondisi tekanan terhadap kawasan ini juga harus diwaspadai terutama dari masyarakat sekitar yang hidup dari mata pencaharian sebagai petani yang berpeluang akan tergiur dengan perambahan hutan untuk memanfaatkan hasil hutan kayu secara ilegal dan juga membuka kawasan pertanian baru. Untuk menghindari kemungkinan ini maka perlu dilakukan pemberdayaan masyarakat sekitar terutama masyarakat dengan usaha ekowisata sehingga masyarakat akan memiliki penghasilan dengan mengelola hutan Kedah tersebut sebagai kawasan ekowisata. 


\section{METODE PENELITIAN}

\subsection{Tempat dan Waktu}

Penelitian dilakukan dikawasan ekowisata Kedah yang terletak di Kecamatan Belangjerango Kabupaten Gayo Lues Provinsi Aceh (Gambar 1). Penelitian dilakukan dari bulan Februari 2019 sampai dengan April 2020

\subsection{Objek dan Ruang Lingkup Penelitian}

Fokus penelitian ini adalah strategi pengembangan kawasan ekowisata Kedah,Kecamatan Blangjerango,Kabupaten Gayo Lues. Ruang lingkup penelitian adalah sebagai berikut:Kelemahan,Kekuatan,Ancaman dan Peluang (SWOT Analysis) yang di amati dari hasil observasi, wawancara dengan DinasLingkungan Hidup, Pariwisata, masyarakat setempat dan wisatawan yang berkunjung.

\subsection{Alat dan Bahan}

Alat yang digunakan, meliputi: laptop, alat perekam, kamera digital (dokumentasi) dan alat-alat lain yang mendukung penelitian ini. Bahan yang digunakan meliputi: peta

kawasan Ekowisata Kedah,75 lembaran kuesioner dan bahan-bahan lain yang mendukung penelitian ini.

\subsection{Teknik Pengambilan Sampel}

Penentuan lokasi penelitian dan wawancara dilakukan dengan metode Purposive Sampling, yaitu pengambilan sampel dilakukan secara sengajadan didasarkan atas adanya tujuan tertentu (Arikunto, 2010).Sampel terpilih merupakan stakeholderyang mempunyai keterkaitan dengan kawasan ekowisata Kedah.Wawancara dan pengisian kuisioner melibatkan pengelola kawasanekowisata Kedah, Pemerintah, Akademisi, Pemerintah Desa, masyarakat setempat, Pengunjung dan pemandu wisata. Jumlah sampel dan rincian yang menjadi responden, tertera pada Tabel 1.

Tabel 1. Kelompok dan Jumlah Responden

\begin{tabular}{clc}
\hline No & \multicolumn{1}{c}{ Kelompok Sampel } & Jumlah Responden \\
\hline 1 & Pengelola kawasan ekowisata Kedah (pemilik) & 2 \\
2 & Dinas pariwisata Gayo Lues & 2 \\
3 & Dinas Lingkungan Hidup Gayo Lues & 2 \\
4 & Masyarakat di sekitar Kedah & 25 \\
5 & Akademisi & 5 \\
6 & Aparat desa & 4 \\
7 & Wisatawan/Pengunjung & 30 \\
8 & Pemandu wisata & 5 \\
\hline & $\quad$ Total & 75 \\
\hline
\end{tabular}




\subsection{Jenis dan Sumber Data}

Jenis dan sumber data yang digunakan dalam penelitian ini yaitu data primer berupa data hasil wawancara mendalam dan observasi dilapangan dan data sekunder berupa dokumen, arsip, literature, hasil penelitian (jurnal) sebelumnya yang berkaitan dengan penelitian ini.

(1) Data primer, yaitu data yang diperoleh secara langsung di lapangan dengan melalui wawancara/kuisioner dan observasi langsung. Adapun data yang diambil melalui observasi langsung serta pengamatan fisik objek panorama alam.

(2) Data sekunder yaitu data yang diperoleh dari berbagai instansi atau lembaga terkait yang relevan dengan penelitian ini meliputi: (a) Keadaan geografis wilayah penelitian, ((b) Data demografis penduduk, (c) Data sarana dan prasarana lokasi penelitian, dan (Balai Konservasi Sumberdaya Alam) Dinas Pariwisata, Dinas

Lingkungan Hidup dan Kehutanan Kabupaten Gayo Lues serta UPTD (Unit Pelaksana Teknis Daerah) yang mengelola Kawasan Kedah Gayo Lues.

\subsection{Analisis Data}

Analisis data dilakukan dengan menggunakan dua metode yaitu :

(1) Metode analisis kualitatif deskriptif, yaitu metode analisis yang bertujuan untuk menggambarkan dan menjelaskan hasil yang diperoleh dalam penelitian terhadap jumlah dan jenis potensi objek wisata (Sugiyono, 2013).

(2) Metode analisis SWOT (Strenghts, Opportunities, Weaknesses, Threats) yaitu metode yang digunakan untuk menentukan strategi pendekatan pengembangan dari faktor kekuatan (S), kelemahan (W), peluang (O) dan ancaman (T) terhadap kondisi yang ada pada kawasan Kedah. Adapun alat yang dipakai dalam metode analisis SWOT yaitu dengan menggunakan matriks SWOT.

(3) Matriks SWOT adalah alat untuk menyusun faktor-faktor strategis organisasi yang dapat menggambarkan secara jelas bagaimana peluang dan ancaman eksternal yang dihadapi organisasi/manajemen dapat disesuaikan dengan kekuatan dan kelemahan Internal yang dimiliki (Juankhan, 2008). Secara rinci Matriks SWOT tertera pada Tabel 2 
Tabel 2. Diagram Matrik SWOT (Strength, Weakness, Opportunity, Treat)

\begin{tabular}{|c|c|c|}
\hline $\begin{array}{r}\text { Faktor Internal } \\
(\text { Internal } \\
\text { factors })\end{array}$ & $\begin{array}{l}\text { Kekuatan } \\
\text { (Strengths) }\end{array}$ & $\begin{array}{c}\text { Kelemahan } \\
\text { (Weaknesses) }\end{array}$ \\
\hline $\begin{array}{l}\text { Faktor Eksternal } \\
((\text { External factors })\end{array}$ & & \\
\hline $\begin{array}{l}\text {-Peluang } \\
\text { (Opportunities) } \\
\text {-Ancaman (Threats) }\end{array}$ & $\begin{array}{l}\text {-Strategi } \\
\text { Kekuatan-Peluang (S-O) } \\
\text {-Stategi } \\
\text { Kekuatan-Ancaman (S-T) }\end{array}$ & $\begin{array}{l}\text {-Strategi } \\
\text { Kelemahan-Peluang (W-O) } \\
\text {-Stategi } \\
\text { Kelemahan-Ancaman(W-T) }\end{array}$ \\
\hline
\end{tabular}

Sumber: Rangkuti, 2006. 


\section{BAB IV HASIL DAN PEMBAHASAN}

\subsection{Karakteristik Responden}

\subsubsection{Jenis Kelamin}

Masyarakat pengunjung yang melakukan kunjugan ke ekowista Kedah Gayo Lues tidak hanya dilakukan oleh pihak laki-laki melainkan juga para perempuan. Jika dilihat dari persentase jenis kelamin wisatawan yang penulis jadikan resnponden dalam penelitian ini dapat dilihat pada tabel di bawah ini.

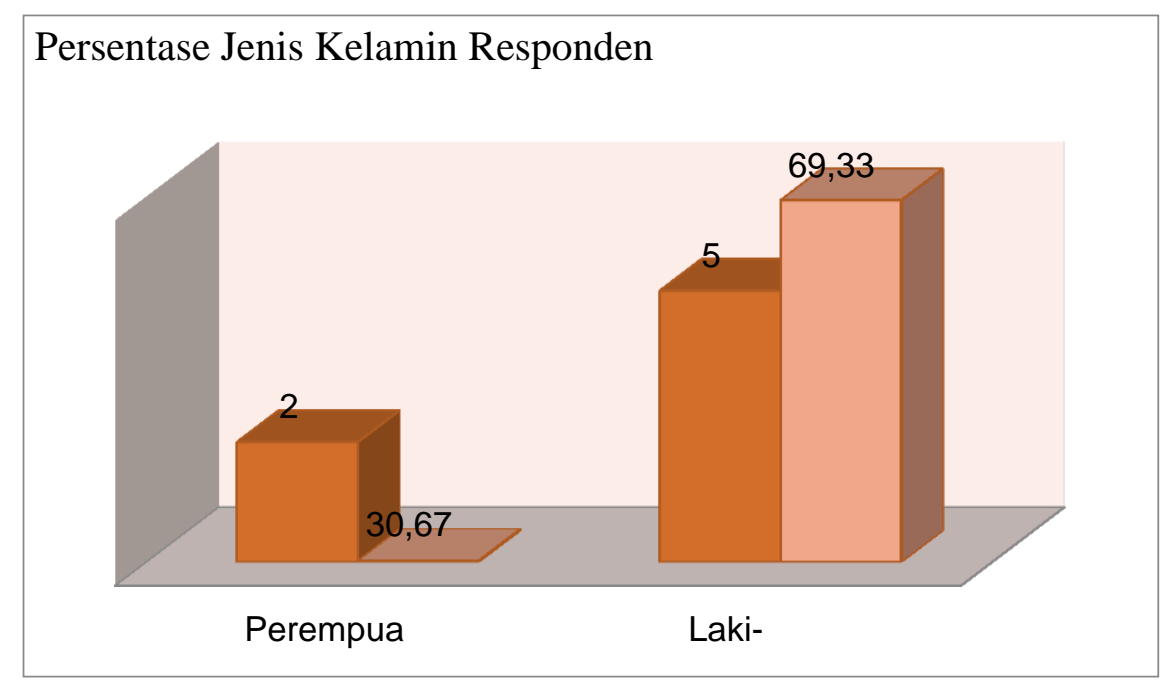

Grafik 4.1Jumlah dan Persentase Jenis Kelamin

Berdasarkan grafik 4.1 di atas maka dapat dijelaskan bahwa responden yang dijadikan sampel penelitian didominasi oleh responden berjenis kelamin laki-laki. Dari 75 (100\%) responden terdapat 69,33\% responden berkelamin laki-laki dan 30,67\% responden berkelamin perempuan.

\subsubsection{Usia Responden}

Usia, di mana usia respondendiklasifikasikan ke dalam empat golongan yaitu golongan 20-30 tahun, 31-40 tahun, 41 - 50 tahun dan>50 tahun. Klasifikasi usia ini juga didasarkan kepada pengetahuan responden terhadap lokasi penelitian. Rentang usia ini semuanya dikategorikan ke dalam usia dewasa. Dari hasil kuesioner yang diperoleh maka terlihat beragam usia responden didalam Grafik 4.2 seperti ditampilkan di bawah ini. 


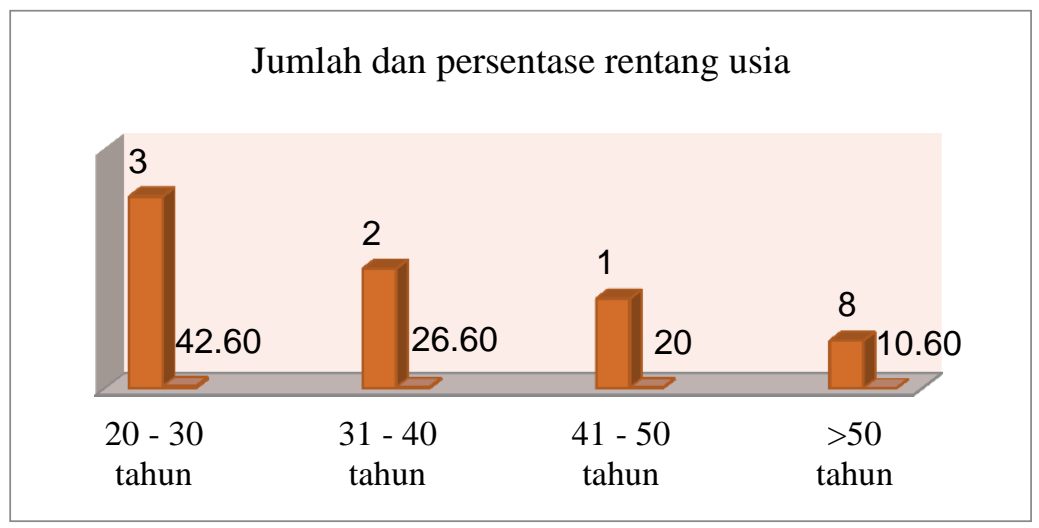

Grafik 4.2 Distribusi dan rentang usia responden

Berdasarkan grafik 4.2 di atas maka terlihat bahwa distribusi usia responden adalah sebagai berikut: 20 - 30 tahun 32 orang (42,60\%), 31 - 40 tahun 20 orang (26,60\%), 41-50 tahun 15 orang $(20 \%)$ dan pada usia $>50$ tahun 8 orang $(10,60 \%)$.

\subsubsection{Pekerjaan Responden}

Dominasi pekerjaan responden yang didapat adalah petani, dimana persentasenya $28,5 \%$ untuk jenis pekerjaan petani, PNS 6,75\%, pegawai swasta 5,25\%, IRT 7,5\%, wiraswasta $2,25 \%$ dan pedagang $6 \%$ (Grafik 4.3 ).

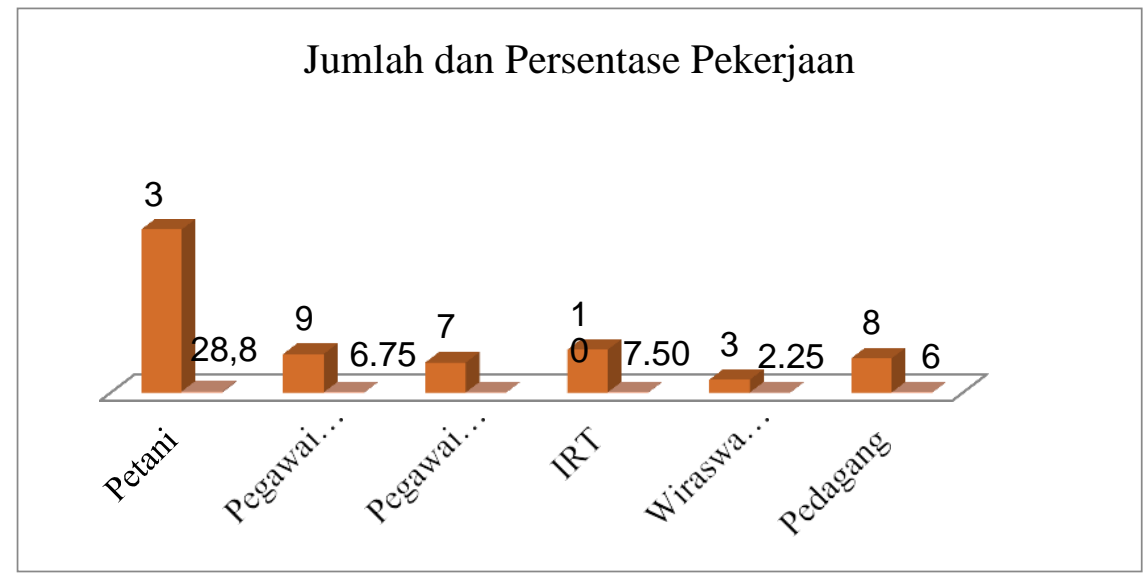

Grafik 4.3 Distribusi Pekerjaan Responden 


\subsubsection{Pendidikan Responden}

Tingkat pendidikan responden yang melakukan kunjugan ke wisata Kedah jugaberagam, mulai dari tingkat pendidikanSD, SMP, SMA, S1 dan bahkan sebagian jugasudah menyelesaikan sarjana $\mathrm{S}-2$, sebagaimana yang terdapat pada grafik 4.4.

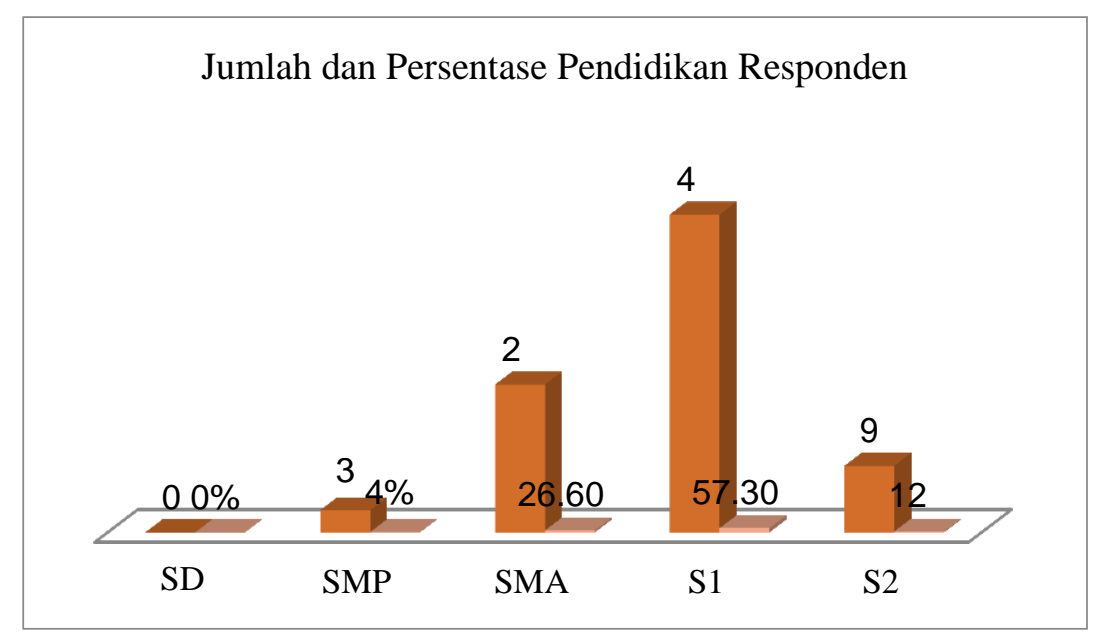

Grafik 4.4Distribusi Pekerjaan Responden

Tabel 4.4 di atas menunjukan bahwa 57,3\% responden berpendidikan S-1, 26,6\% responden berpendidikan SMA, $12 \%$ responden tamatan atau sedang kuliah $\mathrm{S}-2$, responden berpendidikan SMP 4\%, namun tidak ada sama sekali responden yang tidak bersekolah atau berpendidikan tamat SD. 


\section{KESIMPULAN}

\subsection{Kesimpulan}

Berdasarkan hasil penelitian dan pembahasan di atas, maka dapat disimpulkan sebagai berikut: Berdasarkan identifikasi faktor internal pengelolaan ekowisata Kedah terdapat permasalahan pengelolaan yaitu: Kurangnya dukungan dari Pemerintah tentang Pengelolaan Ekowisata Kedah,Belum adanya pengurus yang terstruktur dalam upaya pengembengan wisata Kedah, Fasilitas yang belum memadai di Wisata Kedah, Tidak adanya ciri khas khusus yang dapat menghibur pengunjung seperti kesenian tradisional dan sebagainya, Tingkat SDM masyarakat setempat dalam pengembangan wisata Kedah masih tergolong lemah. Dan dari hasil pengamatan dan analisis yang telah dilakukan dapat disimpulkan bahwa strategi dalam pengelolaan Ekowisata Kedah yaitu:

1. Meningkatkan pengetahuan masyarakat wisata dengan sosialisasi pembangunan berkelanjutan oleh PEMDA dan lembaga pendidikan lainnya sehingga SDM masyarakat setempat lebih berinovasi.

2. Menciptakan kemudahan akses dalam meningkatkan kemudahan kunjungan bagi wisatawan.

3. Meningkatkan peran masyarakat dalam pengelolaan Wisata Kedah

4. Membuat kebijakan dalam menjaga kebersihan lingkungan wisata sebagai contoh kecil membuat rambu-rambu peringatan

5. Memberikan sosialisasi atau pemahaman kepada masyarakat dalam dalam menyikapi budaya negatif dari wisatawan

6. Memberikan sosialisasi kepada masyarakat dalam pemanfaatan lahan pemukiman maupun pertanian berdasarkan fungsi pemanfaatan kawasan

7. Memberikan kepastian hak pengelolaan bagi masyarakat setempat. 


\section{DAFTAR PUSTAKA}

Prasiasa, D. 2011. Wacana Kontemporer Pariwisata. Salemba Humanika. Jakarta. 75 p.

Undang-Undang Republik Indonesia Nomor 10.Tahun 2009 tentangKepariwisataan. Buku Panduan Museum Benteng Vredeburg, Yogyakarta.

FandelidanMukhlison, 2000. Pengertian dan Konsep Dasar Ekowisata.Fakultas Kehutanan, Universitas Gajah Mada (UGM).Yogyakarta. 5 p. 